\title{
Lipid Composition of Winged Bean (Psophocarpus tetragonolobus)
}

\author{
Seiichi Homma, Mutsuko OMACHI, ${ }^{*}$ Atsuko TAMURA, \\ Elly ISHAK, ${ }^{* *}$ and Masao FUJIMAKI ${ }^{1}$ \\ Department of Nutrition and Food Science, Ochanomizu University, \\ Ohtsuka, Bunkyo-ku, Tokyo 112, Japan
}

(Received January 13, 1983)

\begin{abstract}
Summary The lipids were extracted from the winged bean (Psophocarpus tetragonolobus) seed with water-saturated $n$-butanol. Lipids were separated into groups by preparative TLC on silica gel G. The amount of each lipid type was determined by analysis of the fatty acid constituents in each lipid type.

Glyceride was the major lipid accounting for $89.6 \%$ of the total, followed by an unknown lipid 4\%, free fatty acid of $2.3 \%, 1,3$-diglyceride, $1,2-$ diglyceride and steryl ester as $1 \%$ each and finally a polar lipid as $0.2 \%$. The results show that winged bean oil should be suitable for edible purposes. Triglycerides showed a similar profile of fatty acids to those of whole lipid: the major fatty acids were palmitic $(10.9 \%)$, stearic $(4.5 \%)$, oleic $(37.1 \%)$, linoleic $(19.0 \%)$, eicosenoic $(3.6 \%)$, behenic $(18.5 \%)$ and lignoceric $(4.2 \%)$ acids. Compared to soybean oil, winged bean oil contained long chain fatty acids and a fairly small amount of linolenic acid which is favorable regarding oil stability against autoxidation.
\end{abstract}

Key Words winged bean, lipid composition, Psophocarpus tetragonolobus, triglyceride, behenic acid, lignoceric acid

The winged bean plant (Psophocarpus tetragonolobus) is being utilized as a food resource in tropical areas $(1 a, b)$. All parts of the plants such as leaves, seeds, tubers and nodules can be used as protein and vitamin sources in human and animal nutrition. Young leaves and immature pods are cooked as vegetables. Although the mature seed of winged bean is the sole part of the plant which is readily dried for long preservation, it has not been processed into food to the same extent as soybean. Because of the possibility of using the mature seed as a source of edible oil, this study was undertaken to determine the composition of the lipid in the matured seed of winged bean.

1 本間清一, 大町睦子, 田村敦子, エリ・イシャク, 藤巻正生

* Present address: Kwassui Women's Junior College, 1-50, Higashiyamate, Nagasaki 850, Japan.

** Present address: Faculty of Agriculture, Hasanuddin University, Baraya, Ujung Pangdang, Indonesia. 


\section{MATERIALS AND METHODS}

Winged bean. The winged bean analyzed was grown and harvested in the suburbs of Jakarta between the period of 1979 and 1980. The samples were transported to Japan by air and were immediately stored at $4^{\circ} \mathrm{C}$ without fumigation. The samples were subjected to analysis within 2 years after harvesting. The approximate composition of the winged bean seed was determined by the usual AOAC routine procedures.

Extraction of lipid. Winged bean was pulverized in a coffee mill and homogenized with 5 parts of water saturated $n$-butanol for 90 min at ambient temperature, following which the extract was filtered. This extraction procedure was repeated 4 times. The extracts were combined and the solvents were evaporated to dryness in vacuo. The condensed material was immediately dissolved in chloroform-methanol (2:1) and water was added to make a mixed solvent system of chloroformmethanol-water $(8: 4: 3)$ which was then mixed by gentle swirling. The upper layer was discarded, and the chloroform lower layer was washed twice with the same upper layer solvent in order to eliminate non-lipid substances (2). The chloroform layer was dehydrated with anhydrous sodium sulfate, and the lipid sample obtained by evaporation of the solvent in vacuo. The yield of lipid was about $85 \%$.

Gas chromatography of fatty acid. The preparation of fatty acid methyl ester was carried out using a boron trifluoride system (3) with heptadecanoic acid serving as an internal standard. The mixture of methyl esters was analyzed using a $3.1 \mathrm{~m} \times$ $3.1 \mathrm{~mm}$ (i.d.) glass column packed with $15 \%$ dimethyleneglycol succinate on Shimalite (60-80 mesh), using a Shimadzu GC-7A gas chromatograph equipped with a flame ionization detector. Nitrogen carrier gas was used at a flow rate of $50 \mathrm{ml} / \mathrm{min}$. The temperature of the column was programmed at $197^{\circ} \mathrm{C}$ for $32 \mathrm{~min}$ and raised to $210^{\circ} \mathrm{C}$ at a rate of $2^{\circ} \mathrm{C} / \mathrm{min}$.

Separation of the lipid into groups. Lipid was dissolved in chloroform and applied on a thin layer plate of silica gel G (Merck Art 5724). The development was carried out with the solvent system petroleum ether-diethyl ether-acetic acid $(70: 30: 1)$. Authentic standards were developed together for detection purposes. Lipid was visualized by charring with $50 \%$ sulfuric acid, glycolipid was detected by $\alpha$-naphthol, phospholipid by phosphomolybdenic acid, and sterol by sulfuric acidacetic acid (4).

In order to perform preparative separation of lipid into groups, lipid was streaked on a thin layer plate $(20 \times 20 \mathrm{~cm})$ of silica gel $\mathrm{G}$ of $0.5 \mathrm{~mm}$ thickness. The plate was developed with the same solvent system as described above, and the bands of lipid were detected in iodine vapor. Each band was scraped off, and the silica gel eluted with ethyl ether containing the internal standard.

Determination of lipid group. The amount of fatty acid in each lipid group was determined by GLC after methyl esterification of each lipid using the boron trifluoride-methanol system (3). Esterification was performed in a sealed test tube, and was allowed to stand in a boiling water bath for a reaction time of $45 \mathrm{~min}$ for 
steryl ester and triglyceride, $2 \mathrm{~min}$ for free fatty acid, $10 \mathrm{~min}$ for mono and diglycerides, and $30 \mathrm{~min}$ for phospholipid and glycolipid. After esterification, methyl ester was extracted with two volumes of hexane, after which it was washed with equal volumes of water. The amount of each lipid group was calculated by multiplying the total amount of fatty acid methyl esters with conversion factors (2).

\section{RESULTS AND DISCUSSION}

Fatty acid composition of winged bean seed oil

The approximate composition of the winged bean seed is shown in Table 1, yielding an oil content of $15.5 \%$ as determined by ether extraction. This value approximates that of soybean. Table 2 , however, shows the fatty acid composition of the winged bean seeds differs from that of the soybean. Oleic and linoleic acids were the major unsaturated fatty acids present, with oleic acid representing the largest amount. Behenic acid was the major saturated fatty acid, followed by palmitic and lignoceric acids. Compared to soybean, the winged bean has a very small amount of linolenic acid but has large amounts of long chain fatty acids such as behenic acid and lignoceric acid. Eicosenoic acid, which is scarcely detected in soybeans is present in a small amount $(3.9 \%)$ in the winged bean. Although Cerny $e t$ al. speculated on the presence of parinaric acid in the winged bean from the

Table 1. Approximate composition of winged bean. ${ }^{\mathrm{a}}$

\begin{tabular}{lc}
\hline Moisture & $8.9 \%$ \\
Protein $(\mathrm{N} \times 6.25)$ & 38.5 \\
Fat & 15.5 \\
Carbohydrate & 15.7 \\
Ash & 3.9 \\
Fibre & 17.5 \\
\hline
\end{tabular}

${ }^{a}$ Winged bean was harvested in Indonesia (1979-1980).

Table 2. Fatty acid composition of winged bean lipid.

\begin{tabular}{lc}
\hline Myristic acid & $0.1 \%$ \\
Palmitic acid & 8.8 \\
Palmitoleic acid & 0.4 \\
Stearic acid & 5.3 \\
Oleic acid & 36.0 \\
Linoleic acid & 24.8 \\
Linolenic acid & 1.0 \\
Arachidic acid & 1.4 \\
Eicosenoic acid & 3.9 \\
Behenic acid & 14.9 \\
Lignoceric acid & 3.4 \\
\hline
\end{tabular}


retention time on GLC(5), the results obtained here are more in agreement with those of Iwai et al.(6-8).

The composition of the lipid groups of winged bean

Water-saturated $n$-butanol extract was separated into lipid groups by TLC and each lipid group was determined by multiplying the amount of fatty acid present with the respective conversion factors. The thin layer chromatographic profile is

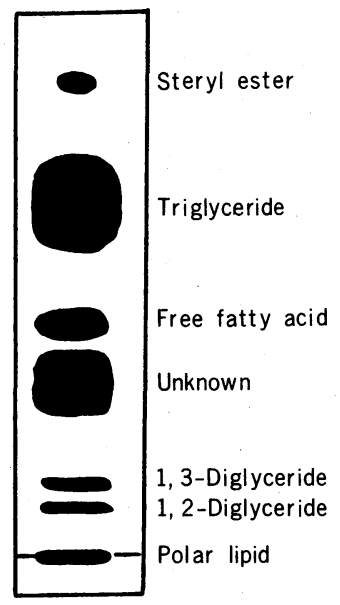

Fig. 1. TLC separation of winged bean lipid on silica gel G. TLC was developed with petroleum ether-diethyl ether-acetic acid $(70: 30: 1)$, and visualized by charring with $50 \% \mathrm{H}_{2} \mathrm{SO}_{4}$.

Table 3. Composition of lipid group in winged bean (wt.\%).

\begin{tabular}{llrrrrrrr}
\hline Fatty acid & & $\begin{array}{c}\text { Steryl } \\
\text { ester }\end{array}$ & $\begin{array}{l}\text { Tri- } \\
\text { glyceride }\end{array}$ & $\begin{array}{c}\text { Free fatty } \\
\text { acid }\end{array}$ & Unknown & $\begin{array}{l}\text { 1,3-Di- } \\
\text { glyceride }\end{array}$ & $\begin{array}{r}1,2-D i- \\
\text { glyceride }\end{array}$ & $\begin{array}{c}\text { Polar } \\
\text { lipid }\end{array}$ \\
\hline Myristic & $(14: 0)$ & - & 0.1 & 1.2 & $1: 0$ & 1.0 & 1.8 & 6.9 \\
Palmitic & $(16: 0)$ & 35.6 & 10.9 & 18.3 & 21.7 & 21.0 & 25.4 & 26.3 \\
Palmitoleic & $(16: 1)$ & 4.8 & trace & 0.2 & 0.6 & 0.4 & 1.0 & 1.0 \\
Stearic & $(18: 0)$ & 17.8 & 4.5 & 11.9 & 9.7 & 9.7 & 10.9 & 10.7 \\
Oleic & $(18: 1)$ & 24.3 & 37.1 & 23.7 & 24.8 & 35.4 & 32.7 & 30.6 \\
Linoleic & $(18: 2)$ & 9.1 & 19.0 & 9.6 & 14.1 & 14.9 & 17.0 & 16.6 \\
Linolenic & $(18: 3)$ & trace & 0.4 & trace & 2.4 & trace & trace & 0.3 \\
Arachidic & $(20: 0)$ & trace & 1.7 & 3.0 & 3.2 & 1.2 & 0.8 & 1.5 \\
Eicosenoic & $(20: 1)$ & trace & 3.6 & 2.1 & 4.7 & 1.6 & 2.3 & trace \\
Behenic & $(22: 0)$ & 4.8 & 18.5 & 23.7 & 14.9 & 12.6 & 6.2 & 6.1 \\
Lignoceric & $(24: 0)$ & 3.6 & 4.2 & 6.3 & 2.9 & 2.2 & 1.9 & - \\
\hline Lipid group & & 1.3 & 89.6 & 2.3 & 4.0 & 1.4 & 1.2 & 0.2 \\
\hline
\end{tabular}


shown in Fig. 1, exhibiting steryl ester, triglyceride, free fatty acid, 1,3-diglyceride and 1,2-diglyceride. An unknown spot of lower $R_{f}$ than free fatty acid seems to be overlapped by two other components and for the convenience of calculation, a conversion factor of 1 was applied. The spot at the start is polar lipid which is positive to $\alpha$-naphthol and phosphomolybdenic acid tests, thus corresponding to glycolipid and phospholipid, respectively.

The composition of the total lipid and the fatty acid composition of each lipid group is shown in Table 3. Glyceride constitutes the major lipid as $89.6 \%$ of the total, followed by an unknown lipid of $4 \%$, free fatty acid accounted for $2.3 \%$ and 1,3-diglyceride, 1,2-diglyceride and steryl ester for $1 \%$ each and finally polar lipid was $0.2 \%$. The results suggest that the major lipid group of the winged bean oil is triglyceride which is as usually found in oil resources.

\section{The characteristics of fatty acid in each lipid group}

The triglyceride shows a similar profile of fatty acids to that of the whole lipid. The major fatty acids were; oleic, linoleic and behenic acids, followed by palmitic, lignoceric, stearic, eicosenoic and arachidic acids in decreasing order. Linolenic acid and myristic acid are minor constituents and the very small amount of linolenic acid is quite favorable to oil stability against autoxidation. The two diglycerides differ a little in fatty acid composition; palmitic acid is rich in 1,2-diglyceride while behenic acid is rich in 1,3-diglyceride. Palmitoleic acid was determined in both diglycerides. Compared to the diglycerides and the triglyceride, the free fatty acid group characteristically contains small amounts of oleic and linoleic acids. The percentages of saturated fatty acids are larger in the free fatty acid group compared to the triglyceride and diglyceride groups. It is considered that the majority of the saturated fatty acid in the triglycerides are bound to the 1 or 3 position of glycerol, which is more susceptible to hydrolysis by lipase than the saturated fatty acid during storage.

Polar lipid groups are more abundant in medium length fatty acids such as myristic, palmitic and stearic acids than in the triglyceride and 1,3-diglyceride groups, while the profile of the fatty acid composition is similar to that of 1,2diglyceride group. The steryl ester group is rich in palmitic, palmitoleic and stearic acids, and poor in behenic acid compared to the other groups.

Since the oil of winged bean contains $89.6 \%$ triglyceride, it should be a promising oil resource. Triglyceride contains characteristically a small percentage ( $c a .20 \%$ ) of the polyunsaturated fatty acids, linoleic and linolenic acid, and may be relatively more stable against autoxidation because of the small content of linolenic acid. The triglycerides also have long chain fatty acids, namely behenic acid and lignoceric acid, however, which might be difficult to digest. Cerny et al., in a nutritional study, showed that toxic effects caused by poor digestibility were not observed when winged bean flour contained oil with behenic acid. Further nutritional tests should be made on the oil extracted from the seed as instead for use as a cooking and salad oil. When the extracted oil was allowed to stand in a 
refrigerator, a fair amount of oil became solid. A wintering process would therefore be essential to the refining process. In a succeeding report the composition of triglyceride will be described.

This work was supported in part by Grant-in-Aids for Scientific Research (No. 56040018 and 5606008) from the Ministry of Education, Science and Culture of Japan.

\section{REFERENCES}

1a) National Academy of Sciences (1975): The Winged Bean: A High Protein Crop for the Tropics, Washington, D.C.

1b) Philippine Council for Agriculture and Resources Research (1980): The Philippines Recommends for Winged Bean. Los Baños.

2) MacMurry, T. A., and Morrison, W. R. (1970): Composition of wheat-flour lipids. J. Sci. Food Agric., 21, 520-528.

3) Morrison, W. R., and Smith, L. M. (1964): Preparation of fatty acid methyl esters and dimethylacetals from lipids with boron fluoride-methanol. J. Lipid Res., 5, 600-608.

4) Kates, M. (1975): Techniques of Lipidology, American Elsevier Publishing Co., Inc., New York, p. 502.

5) Cerny, K., Kordylas, M., Pospisil, F., Svabensky, O., and Zajik, B. (1971): Nutritive value of the winged bean (Psophocarpus palustris Desv.). Br. J. Nutr., 26, 293-299.

6) Higuchi, M., Terao, J., and Iwai, K. (1982): Gas chromatography-mass spectrometric determination of fatty acids in seed oil of winged bean (Psophocarpus tetragonolobus (L.) DC). J. Nutr. Sci. Vitaminol., 28, 511-518.

7) Garcia, V. V., Palmer, J. K., and Young, R. W. (1979): Fatty acid composition of the oil of winged bean, Psophocarpus tetragonolobus (L.) DC. J. Am. Oil Chem. Soc., 56, 931-932.

8) Ekpenyoung, T. E., and Borchers, R. L. (1980): The fatty acid composition of the oil of the winged bean (Psophocarpus tetragonolobus L.) seeds. J. Am. Oil Chem. Soc., 57, 147-149. 